\title{
Profile of sport competition anxiety trait and psychological coping skills among secondary school athletes in Enugu State, South East Nigeria
}

Authors' Contribution: A Study Design B Data Collection C Statistical Analysis D Data Interpretation

E Manuscript Preparation

F Literature Search

G Funds Collection
Tochi Emmanuel Iwuagwu ${ }^{A B C D E F}$, Joshua Emeka Umeifekwem ${ }^{A B C D}$, Samuel Ndubuisi Igwe ${ }^{\mathrm{BDEF}}$, Okechukwu Kingsley Oforka ${ }^{\mathrm{BF}}$, Oluchukwu Precious Udeh ${ }^{\mathrm{BF}}$

Department of Human Kinetics and Health Education, University of Nigeria, Nsukka, Enugu State, Nigeria

\section{abstract}

Background: The study investigated the profile of sport competition anxiety trait and psychological coping skills (PCS) among secondary school athletes in Enugu State, South East Nigeria.

Material and methods:

Conclusions:

Key words:

Conclusions:

A total number of 420 secondary school athletes participated in a cross-sectional study. The profile of sport competition anxiety trait and psychological coping skills of the participants were measured using a 46-item questionnaire consisting of three socio-demographic factors as part I, a 15-item Sport Competition Anxiety Test (SCAT) as part II and a 28-item Athletic Coping Skills Inventory (ACSI) as part III. Mean, standard deviation and linear regressions were used for analyses.

Results: The findings revealed that secondary school athletes had an average level of anxiety (mean $\pm \mathrm{SD}=20.79 \pm 3.776$ ), and greater strength on psychological coping skills (mean $\pm \mathrm{SD}=49.92 \pm 19.20$ ) while participating in sport competitions. Coachability, Goal setting and mental preparation, and Freedom from worry had significant association $(p<.05)$ with athletes' Sport Competition Anxiety.

This research proves that increase in psychological coping skills leads to increase in athletes' competition anxiety while participating in sport. However, sport psychologists, Physical Education teachers, games masters/mistresses and coaches in secondary schools need to acquire psychological skills through specialized seminar or expertise training so as to enable athletes to cope with sport anxiety.

\section{article details}

Article statistics:

Full-text PDF:

Copyright

Indexation:

Funding:

Conflict of interests:

Corresponding author:

Open Access License:
Word count: 6,181; Tables: 5; Figures: 0; References: 51

Received: March 2021; Accepted: October 2021; Published: December 2021

http://www.balticsportscience.com

Gdansk University of Physical Education and Sport, Poland

Celdes, Clarivate Analytics Emerging Sources Citation Index (ESCI), CNKI Scholar (China National Knowledge Infrastructure), CNPIEC, DOAJ, EBSCO - Central \& Eastern European Academic Source, EBSCO - SPORTDiscus, EBSCO Discovery Service, Google Scholar, Index Copernicus, J-Gate, Naviga (Softweco, Primo Central (ExLibris), ProQuest - Family Health, ProQuest - Health \& Medical Complete, ProQuest - Illustrata: Health Sciences, ProQuest Nursing \& Allied Health Source, Summon (Serials Solutions/ProQuest, TDOne (TDNet), Ulrich's Periodicals Directory/ ulrichsweb, WorldCat (OCLC)

This research received no specific grant from any funding agency in the public, commercial, or not-for-profit sectors. Authors have declared that no competing interest exists.

Okechukwu Kingsley Oforka, Department of Human Kinetics and Health Education, University of Nigeria, Nsukka, +2348066554268; kingsley.oforka@unn.edu.ng

This is an open access article distributed under the terms of the Creative Commons Attribution-Non-Commercial-NoDerivatives 4.0 International (https://creativecommons.org/licenses/by-nc-nd/4.0/), which permits use, distribution, and reproduction in any medium, provided the original work is properly cited, the use is non-commercial and is otherwise in compliance with the license. 


\section{INTRODUCTION}

Sport represents competitive surrounding filled with stressful situations where athletes usually have to perform at optimum levels in high-pressure circumstances that can influence their performance. Many psychological factors could influence or be associated with athletes' performance in sports contests.

In sports, competition carries various threats, including anxiety which has a significant effect on the overall physiological, psychological and behavioural performance of the athlete or player [1]. It is estimated that 52 million youngsters participate in sport, and participation in sports is associated with numerous physical and psychological benefits including improved cardiovascular functioning, a higher level of self-esteem and body image satisfaction [3].

Although participation in sports could be a rewarding and refreshing experience, competitive sport itself elicits some form of anxiety and apprehension in participants [4]. Winning in a competition depend on how an athlete can control his or her anxiety level. Anxiety is a negative emotional state characterized by nervousness, feelings of tension, worry, and apprehension and bodily arousal which may sometimes have a beneficial but mostly detrimental effect upon sport performance [5].

In competitive sports, every athlete experiences one form of anxiety or the other, before, during or after events [9]. Competitive anxiety in sport could make the world most successful athlete feel nervous. Poor performance tends to increase the level of competitive anxiety [2], a fact which may be attributed to the low level of self-confidence among athletes following a defeat. Several studies have analysed the relationships between the variables included in the sports psychological profile [7, 8] with competitive anxiety. Sport Competition Anxiety (SCA) is the feelings of nervousness and tension caused by the competitive environment or surrounding expectation that is related to arousal.

There are two types of sport competition anxiety: state and trait. State anxiety refers to ever-changing mood components (emotional state, perceived feeling of apprehension and tension, accompanied by or associated with activation or arousal of the automatic nervous system [5], paralyzing fear, inability to concentrate, and sweating, shaking, shortness of breath, dizziness, increased heart rate and butterfly in the stomach) [9]. Trait anxiety is part of personality, and is an acquired behavioural tendency or disposition that influences behaviour [5]. This study focuses on trait anxiety.

Various factors have been adduced to be associated with SCA and Psychological Coping Skills (PCS). Some factors, such as: gender, age, type of sports among others, could influence the level of anxiety among athletes and pressure to perform during competition. State and trait anxiety levels among different genders of athletes and non-athletes were not significantly different [11]. The athlete's ability to employ different coping skills and strategies to sustain a stable or improve his or her level of performance is duly required at all times. In competitive anxiety, males report using more coping approaches than females [17]. With regards to age, the level of anxiety tends to be higher in groups of young athletes due to the fact that their young age is directly related to factors, such as: feeling of insecurity, emotional dependency and use of less elaborated strategies for coping with the physiological responses [2].

Some athletes are more prone to anxiety than others [6]. Athletes who participate in individual sports have also been found to experience greater anxiety levels than others who play team sports. Athletes who practise individual sports are more anxious during competition because of the responsibility for achieving the result which depends exclusively on one person [2], whereas those practising a team sport would share this responsibility with other members of the team. 
When athletes at any level are under pressure from the demands of their sports and do not have an adequate coping mechanism in place to withstand it, it could usually have a detrimental effect on performance.

The school sports competition provides the conditions and environment for the preparation and development of young secondary school athletes: physically, psychologically and mentally. National athletes who win medals for their countries are usually athletes who started participating in sports right from their secondary school days that have developed some coping strategies. Emerging evidence [20] reveals a poor performance of school athletes at the zonal and state games. The cause of poor performance by these athletes in competition is attributed to many factors among which poor management of SCA could also play a major role. Research is yet to study the characteristics of SCA and PCS makeup of secondary school athletes in the study area as a contributory factor to poor sports performance. Again, research in this area among Nigerian secondary schools is scarce. Therefore, given the need to obtain data to better understand athletes and how they relate to sports performance anxiety, the study was designed to assess the profile of SCA trait and PCS among secondary school athletes in Enugu State, South East Nigeria. Understanding athletes' SCA and PCS would provide insight and explanations regarding contributory factors to poor performance of athletes in inter-school or state games and the psychological coping skills needed to be adopted before and during sport competitions.

\section{MATERIAL AND METHODS}

\section{STUDY DESIGN AND SETTING}

A cross-sectional study was conducted between December, 2019 and November, 2020 at selected secondary schools in the three senatorial districts (Enugu North, Enugu West and Enugu East) that make up Enugu State, South East Nigeria. The senatorial districts are made up of Local Government Areas (LGAs). In the various LGAs, there are autonomous communities and villages.

\section{PARTICIPANTS}

The study sample comprised secondary school athletes aged between 10 and 21 years. All the participants met the inclusion criteria of regularly practicing and competing in organized sports as well as having represented their schools in sport meetings or competitions in the past 12 months. Each of the schools in the selected area shows considerable interest in sports and participates in respective sport competitions, such as: inter-house sports, interzonal competitions. The study included male (86.2\%) and female (13.8\%) athletes with mean age $(\mathrm{M}=16.00$, younger $=46.6 \%$, older $=53.4 \%)$, and team $(79.5 \%)$ and individual (20.5\%) sport type.

\section{SAMPLING PROCEDURES}

The sample size for the study was determined using the sample size determination formula [21]. Based on the expected proportion of the anxiety level and the psychological coping skills usage level (50\%), we calculated a sample size of 420 that would be required to give a 95\% probability measuring the profile of Sport Competition Anxiety Trait and psychological coping skills with $50 \%$ accuracy, a none response rate of $10 \%$.

The purposive sampling method was adopted in selecting 60 secondary schools; 20 from each of the three senatorial districts that make up Enugu State, South East Nigeria. However, seven secondary school athletes were drawn from each of the selected 60 schools in Enugu State, which gave a total sample size of 420 participants for this study. The sampling was purposive in the sense that only secondary school athletes who had represented their schools 
in organized sport meet or competition in the past 12 months were involved. However, school athletes who had not participated in sport competitions in the past 12 months were excluded from the study.

\section{MATERIAL AND MEASURES}

Following the participants' consent, a 46-item Sport Competition Anxiety Test (SCAT) and Athletic Coping Skill Inventory (ACSI) questionnaire was administered for data collection. The questionnaire consisted of three parts. Part I consisted of three socio-demographic variables (gender, age and type of sport). Part II consisted of 15 questions with non-dichotomous response options (rarely, sometimes and often) on the profile of athletes' sport competition anxiety level, while part III consisted of 28 questions with non-dichotomous response options (almost, never, sometimes, often and almost always) on psychological coping skills of athletes.

\section{SPORT COMPETITION ANXIETY TEST (SCAT)}

The Sport Competition Anxiety Test [22, 23], commonly known as just the SCAT test, is a selfreporting questionnaire about anxiety. The SCAT test analyses an athlete's responses to a series of statements about how they feel in a competitive situation, with response options of rarely, sometimes and often. From the results, it is possible to determine a measure of their level of anxiety. The SCAT contains 15 items, 10 of which measure symptoms associated with anxiety, with five others that are spurious (not scored) included to reduce the likelihood of an internal response-set bias. Items 1, 4, 7, 10 and 13 are spurious and scored $=0$, while the score of the other 10 items are summed to provide the overall measure of the anxiety level with a high score reflecting a greater tendency to experience competitive anxiety. The results were evaluated using a Likert scale from one (rarely) to three (often). The developers of SCAT reported a high degree of reliability and good validity of the scale, and results can be ranged between 10 and 30, where higher results indicate higher levels of trait anxiety. The SCAT has demonstrated satisfactory internal consistency with associated Cronbach's Alpha of .95 to .97 reliability [23]. The internal consistency value (Cronbach's Alpha) for this research was .735.

\section{ATHLETIC COPING SKILLS INVENTORY (ACSI)}

The Athletic Coping Skills Inventory (ACSI) is also a standardized instrument developed by Smith et al. [24]. The ACSI contains 28 trait items like measures of psychological coping skills thought to improve coping. The items are categorized according to the seven factors that make up the subscales (Coping with adversity [COPE], Coachability [COACH], Concentration [CONC], Confidence and achievement motivation [CONF], Goal setting and mental preparation [GOAL], Peaking under pressure [PEAK], and Freedom from worry [FREE]); and adequate internal consistency values were obtained ( $\geq .70)$. The results were evaluated using a Likert scale from one (almost) to five (almost always). The internal consistency value (Cronbach's Alpha) for this research was .790.

\section{DATA COLLECTION PROCEDURE}

The current research was developed in accordance with the Ethical Principles of the Psychologists and code of conduct of the American Psychological Association [25], and the research was approved by Research Ethics Committee of the faculty of Education, University of Nigeria, Nsukka (UNN/FE/REC21/001).

In order to recruit athletes, the research team met with the Principals and heads (game masters) of various secondary school sports clubs, requesting the participation of their athletes. After the Principals and game masters' agreement, informed consent was obtained from the athletes, and it was explained to them how and when the data would be taken. Also, the research team explained the objectives of research to the participants, and the latter were assured about the privacy of their personal data. After receiving their consent, the 
researchers administered 420 copies of the SCAT test and ASCI to the respondents through the sports masters for completion. Participants filled out the questionnaires individually and it was only done once. The administration protocol required that two researchers always be present during the procedures to answer participants' questions and ensure that all steps of the protocol were followed. The questionnaires were collected back immediately after filling out in order to ensure the maximum return rate. All the instruments administered were returned, which gave 100\% return rate. Out of the 420 copies of the SCAT test and ASCI returned, 64 were not properly filled out, and they were discarded. Only 356 copies of the SCAT test and ASCI questionnaires were properly filled out and were used for the study analyses.

\section{DATA ANALYSIS}

The IBM Statistical Package for Social Sciences (SPSS) version 23.0 was used for all the statistical analyses. The standard descriptive statistics were applied to describe data pattern. Frequency count, percentage, mean and standard deviation were used to analyse the participants' socio-demographic characteristics as well as the SCAT test and ACSI scores. In the scoring of the SCAT test, a score of less than 17 indicates a low level of anxiety; 17 to 24 an average level of anxiety, and more than 24 a high level of anxiety. In the scoring of the ACSI, the scores are interpreted as follows: subscales 0-12 and the total scale 0-84. Scores range from low of 0 to a high of 12 on each subscale, with higher scores indicating greater strengths on that subscale. The score for the total score ranges from a low of 0 to a high of 84, with higher scores signifying greater strength. These showed that for subscales: less strength $(<6)$; greater strength $(\geq 6)$ and for the full scale: less strength $(<42)$; greater strength $(\geq 42)$ [24]. The normality of the data was checked through skewness, kurtosis and the Kolmogorov-Smirnov (KS) test. Normal distribution was considered if the skewness showed values between -2 and +2 , and the KS test is not significant [26]. In order to adjust the sample to normal, the data of each variable were adjusted using $\operatorname{In}(\mathrm{x})$ and $\mathrm{x}^{2}$ algorithms if they were not normally distributed. The internal consistency of the SCAT and ACSI scales was estimated using Cronbach's Alpha coefficient. The predictive capacity of psychological profile on SCA Trait level and PCS as well their covariates (gender, age and type of sport) was assessed by linear multiple regression analyses. All the tests were 2-tailed, and the probability values less than $0.05(\mathrm{p}<0.05)$ were considered significant.

\section{RESULTS}

Table 1 shows that secondary school athletes had a total mean Sport Competition Anxiety of 20.79. Considering the total athletes' score as recommended by the SCAT designers, secondary school athletes in Enugu State had an average level of anxiety while participating in sport competition.

Table 1. Mean response of the level of sport competition anxiety trait among secondary school athletes $(n=356)$

\begin{tabular}{lcc}
\multicolumn{1}{c}{ Statement } & Athletes' Mean Score & Standard Deviation \\
\hline Before I compete, I feel uneasy & 2.17 & .718 \\
Before I compete, I worry about not performing well & 2.11 & .779 \\
When I compete, I worry about making mistakes & 2.19 & .767 \\
Before I compete, I am calm & 1.81 & .840 \\
Before I compete, I get a queasy feelings in my stomach & 2.02 & .852 \\
Just before competing, I notice my heart beats faster than usual & 2.29 & .791 \\
Before I compete, I feel relaxed & 1.87 & .841 \\
Before I compete, I am nervous & 2.07 & .782 \\
I get nervous wanting to start the game & 2.15 & .781 \\
Before I compete, I usually get uptight & 2.11 & .780 \\
Total SCAT & 20.79 & 3.772 \\
\hline
\end{tabular}

*SCAT score: Less than 17 = low level of anxiety; 17 to 24 = average level of anxiety; More than 24 = high level of anxiety 
Table 2 shows that secondary school athletes in Enugu State had a total mean score of 49.92 on psychological coping skills. This signifies that the athletes had greater strength on psychological coping skills. The table also shows that secondary school athletes had greater strength on the seven dimensions of psychological coping skills (COPE, COACH, CONC, CONF, GOAL, PEAK and FREE).

Table 2. Responses on the usage status of psychological coping skills among secondary school athletes $(n=356)$

\begin{tabular}{llc}
\multicolumn{1}{c}{ Athletes' psychological coping skills } & Mean & Standard Deviation \\
\hline Coping with adversity (COPE) & 7.472 & 3.151 \\
Coachability (COACH) & 6.649 & 3.158 \\
Concentration (CONC) & 7.048 & 3.108 \\
Confidence and achievement motivation (CONF) & 7.655 & 3.171 \\
Goal setting and mental preparation (GOAL) & 7.410 & 3.315 \\
Peaking under pressure (PEAK) & 6.817 & 3.361 \\
Freedom from worry (FREE) & 6.868 & 3.381 \\
Total Scale Score & 49.92 & 19.20 \\
\hline
\end{tabular}

*Key: for subscale: $<6=$ less strength; $\geq 6$ = greater strength. full scale: $<42=$ less strength; $\geq 42$ =greater strength

Results in Table 3 show that the regression model was a significant indicator that the relationship between the independent variables and the dependent variable is strong $(\mathrm{F}=21.827, \mathrm{p}<.001)$. The adjusted $\mathrm{R} 2$ of .291 shows that in the regression model, the independent variables (COPE, COACH, CONC, CONF, GOAL, PEAK, FREE) account for 29\% of the variance in the dependent variable (Sport Competition Anxiety [SCA]), which is modest. Findings revealed that the $\mathrm{COACH}$ score $(\mathrm{B}=.332, \mathrm{p}<.001)$ had significant relationship with athletes' total mean SCA score, as athletes with higher COACH had greater SCA than those with lower COACH. GOAL score $(\mathrm{B}=-.191, \mathrm{p}=.033<0.5)$ had a significant relationship with athletes' total mean SCA score, as athletes with lower GOAL had greater SCA than those with higher GOAL. FREE score $(\mathrm{B}=.480, \mathrm{p}<.001)$ had significant relationship with athletes' total mean SCA score, as athletes with higher FREE had greater SCA than those with lower FREE. Findings further revealed that the COPE score $(B=-.182, p=.059>.05)$, the CONC score $(B=.091, \mathrm{p}=345>.05)$, the CONF score $(\mathrm{B}=.047, \mathrm{p}=.593>.05)$, and the PEAK score $(\mathrm{B}=.037, \mathrm{p}=.610>.05)$ had no significant relationship with athletes' total mean SCA.

Table 3. Linear multiple regression analysis of sport competition anxiety trait and psychological coping skills usage

\begin{tabular}{ccccccc} 
Model & & $\begin{array}{c}\text { Unstandardized } \\
\text { Coefficients (B) }\end{array}$ & $\begin{array}{c}\text { Standard Error } \\
(\mathrm{SE})\end{array}$ & $\begin{array}{c}\text { Standardized } \\
\text { Coefficients (Beta) }\end{array}$ & $\mathrm{t}$ & $\mathrm{p}$-value \\
\hline \multirow{4}{*}{ Constant } & 16.81 & .478 & & 35.16 & .000 \\
& COPE & -.182 & .096 & -.152 & -1.894 & .059 \\
& COACH & .332 & .092 & .278 & 3.601 & $.000^{* * *}$ \\
& CONC & .091 & .096 & .075 & .946 & .345 \\
& CONF & .047 & .088 & .039 & .535 & .593 \\
& GOAL & -.191 & .089 & -.168 & -2.142 & $.033^{*}$ \\
& PEEK & .037 & .073 & .033 & .511 & .610 \\
& FREE & .480 & .079 & .430 & 6.094 & $.000 * * *$ \\
\hline
\end{tabular}

$\mathrm{p}<0.05, * * \mathrm{p}<0.01, * * * \mathrm{p}<0.001$

$\mathrm{R}=.552 ; \mathrm{R}^{2}=.305 ;$ Adjusted $\mathrm{R}^{2}=.291 ; \mathrm{F}=21.827 ; \mathrm{Sig}=.000 ; \mathrm{a}=$ Dependent Variance: Sport Competition Anxiety (SCA) score; $b=$ Independent Variance (constant): Coping with adversity (COPE), Coachability (COACH), Concentration (CONC), Confidence and achievement motivation (CONF), Goal setting and mental preparation (GOAL), Peaking under pressure (PEAK), and Freedom from worry (FREE).

Results in Table 4 show that the regression model was significant, indicating that the relationship between the independent variables and the dependent variables is strong 
$(\mathrm{F}=15.056, \mathrm{p}<.001)$. The adjusted $\mathrm{R}^{2}$ of .106 shows that in the regression model, the independent variables (gender, age, type of sport) account for only $10.6 \%$ of the variance in the dependent variable (Sport Competition Anxiety). Findings revealed that age $(B=$ $1.545, \mathrm{p}<.001$ ) had a significant relationship with athletes' total mean SCA score, as older athletes had greater SCA than younger athletes. The type of sport $(B=2.488, p<.001)$ had a significant relationship with athletes' total mean SCA score, as team sport athletes had greater SCA than individual sport athletes. Findings further revealed that gender $(B=-.406$, $\mathrm{p}=.462>.05$ ) had no significant relationship with athletes' total mean SCA.

Table 4. Linear multiple regression analysis of sport competition anxiety trait and some selected covariates

\begin{tabular}{ccccccc} 
Model & & $\begin{array}{c}\text { Unstandardized } \\
\text { Coefficients (B) }\end{array}$ & $\begin{array}{c}\text { Standard Error } \\
(\mathrm{SE})\end{array}$ & $\begin{array}{c}\text { Standardized } \\
\text { Coefficients (Beta) }\end{array}$ & $\mathrm{t}$ & $\mathrm{p}$-value \\
\hline \multirow{4}{*}{1} & Constant & 15.887 & .998 & & 16.914 & .000 \\
& Gender & -.406 & .551 & -.037 & -.737 & .462 \\
& Age & 1.545 & .380 & .204 & 4.061 & $.000 * * *$ \\
& Type of Sport & 2.488 & .469 & .266 & 5.304 & $.000 * * *$ \\
\hline
\end{tabular}

$* \mathrm{p}<0.05, * * \mathrm{p}<0.01, * * * \mathrm{p}<0.001$

$\mathrm{R}=.337 ; \mathrm{R}^{2}=.114 ;$ Adjusted $\mathrm{R}^{2}=.106 ; \mathrm{F}=15.056 ; \mathrm{Sig}=.000 ; \mathrm{a}=$ Dependent Variance: Sport Competition Anxiety Trait score; $b=$ Independent Variance (constant): Gender, Age and Type of Sport

Results in Table 5 show that the regression model was significant, indicating that the relationship between the independent variables and the dependent variables is strong $(\mathrm{F}=25.619, \mathrm{p}<.001)$. The adjusted $\mathrm{R}^{2}$ of .172 shows that in the regression model, the independent variables (gender, age, type of sport) account for $17 \%$ of the variance in the dependent variable (psychological coping skills), which is modest. Findings revealed that gender $(\mathrm{B}=-6.231, \mathrm{p}=.021<.05)$ had a significant relationship with total mean PCS score, as females had greater PCS than their male counterparts. Age $(B=8.390, p<.001)$ had a significant relationship with the total mean PCS score, as older athletes had greater PCS than younger athletes. The type of sport $(B=16.705, p<.001)$ had a significant relationship with the total mean PCS score, as team sport athletes had greater PCS than individual sport athletes.

Table 5. Linear multiple regression analysis of psychological coping skills and some selected covariates

\begin{tabular}{ccccccc} 
Model & & $\begin{array}{c}\text { Unstandardized } \\
\text { Coefficients (B) }\end{array}$ & $\begin{array}{c}\text { Standard Error } \\
\text { (SE) }\end{array}$ & $\begin{array}{c}\text { Standardized } \\
\text { Coefficients (Beta) }\end{array}$ & $\mathrm{t}$ & $\mathrm{p}$-value \\
\hline \multirow{4}{*}{1} & Constant & 24.009 & 4.885 & & 4.915 & .000 \\
& Gender & -6.231 & 2.697 & -.112 & -2.310 & $.021^{*}$ \\
& Age & 8.390 & 1.862 & .218 & 4.507 & $.000^{* * *}$ \\
& Type of Sport & 16.705 & 2.295 & .352 & 7.279 & $.000^{* * *}$ \\
\hline
\end{tabular}

$* p<0.05, * * p<0.01, * * * p<0.001$

$\mathrm{R}=.423 ; \mathrm{R}^{2}=.179 ;$ Adjusted $\mathrm{R}^{2}=.172 ; \mathrm{F}=25.619 ; \mathrm{Sig}=.000 ; \mathrm{a}=$ Dependent Variance: Psychological Coping Skills score; $\mathrm{b}=$ Independent Variance (constant): Gender, Age and Type of Sport

\section{DISCUSSION}

Research in recent years has shown that several factors may underline the anxiety level and psychological coping skills of athletes in sport competitions and the subsequent high anxiety and low performance in sport competitions. However, this study was undertaken to investigate the profile of sport competition anxiety trait and psychological coping skills of athletes. Table 1 shows that secondary school athletes in Enugu State had an average level of anxiety while participating in sport competition. This finding is expected and not surprising, given the fact that the level of anxiety invariably affects the level of athletes' 
performance. It is normal that some athletes will experience anxiety both prior to and during their performance because they would not like to disappoint their teammates, coaches, family members and fans. It is not only high level professional athletes who experience anxiety today; also college, high school and young athletes succumb to the pressure of competition. The finding is in line with the findings of Hanton et al. [27] who found that different athletes have reported different levels (high to low) of anxiety before and during competition. Meanwhile the findings by Males and Kerr [28] showed that the level of anxiety gradually increased when the sport event was nearer. This implies that, if anxiety is not properly handled or misinterpreted, the athlete will lose control, and the performance level might decrease. Therefore, there is a need to be positive in thinking and have better mental skills to resolve problems that may arise as a result of anxiety. School coaches and sport psychologists need to understand and organize programmes suitable for reduction of stress and anxiety especially during training and competition. Numerous studies have concluded that athletes with higher levels of competitive trait anxiety tend to perceive competitive situations as more threatening than athletes with lower levels of competitive trait anxiety [23]. Both high and low levels of anxiety interfere with performance. However, several theories suggest that some people perform best when their state or trait anxiety is low while some people prefer higher levels of state or trait anxiety [5]. The proximity of competition increases the athlete's level of anxiety because of a threatening competitive environment. In addition, away contests would be influenced by travel, poor familiarity with the venue, away supporters, referee bias and absence of family and social support [29]. Most studies reveal that poor performances tend to increase the level of SCA [2], a fact which may be attributed to the low level of self-confidence among athletes following a defeat. It is argued that knowing an athlete's level of trait anxiety can usually be helpful in predicting his reaction to competition, evaluation, and threatening situations [5].

Athletes had greater strength on psychological coping skills overall and its seven dimensions (COPE, COACH, CONC, CONF, GOAL, PEAK and FREE) (Table 2). The result is expected and not surprising because the athlete's ability to employ different coping skills and strategies to sustain stability or improve the athletes' level of performance is duly required all the time. This is in line with Jones' [30] assertion that at the top sporting level, there is very little difference in the participants' skill levels; thus, it is often the ability to handle arousal, anxiety and stress that separates the winner and loser. Similarly, Mesagno [14] stated that one of the major problems athletes face is their inability to deal with the feelings of arousal under pressure and to perform successfully under pressure.

The findings have implication for the school coaches, sports psychologist to understand and gain knowledge on various measures of coping skills so as to incorporate the training regimen with such knowledge and to train the athlete on the need and use of coping skills to manage demanding or challenging situations in sport activities including competitions. The results could indicate that the development of psychological skills in sportsmen and women would help them to have better emotional sensations linked to competition, and to prepare them to better face challenges [31].

The results have shown statistical significant associations among the studied constructs and a remarkable predictive capacity of the psychological abilities of athletes on competitive anxiety. Linear regressions show that $\mathrm{COACH}$ score had significant relationship with athletes' total mean SCA score, as athletes with higher COACH had greater SCA than those with lower COACH. GOAL score had significant relationship with athletes' total mean SCA score, as athletes with lower GOAL had greater SCA than those with higher GOAL. FREE score had significant relationship with athletes' total mean SCA score, as athletes with higher FREE had greater SCA than those with lower FREE. Also, COPE score, CONC score, CONF score, and PEAK score had no significant relationship with athletes' total mean SCA (Table 3). This 
would indicate the importance of training athletes on psychological skills, especially coping strategies for negative situations, as one of the tools the athlete could develop to avoid the development of competitive anxiety states [32,33]. When an athlete at any level is under pressure from the demands of their sports and does not have adequate coping mechanism in place, it can have a detrimental effect on performance. The findings are in line with the report by Nicholls et al. [34], who stressed that athletes need to learn coping mechanisms for handling stress and anxiety in different situations, and there is a need to be focused on increasing the amount and diversity of coping styles, since suppressing and ignoring stress and anxiety has a negative impact on an individual wellbeing.

Table 4 shows that age had a significant relationship with athletes' total mean SCA score, as older athletes had greater SCA than younger athletes. The type of sport had a significant relationship with athletes' total mean SCA score, as team sport athletes had greater SCA than individual sport athletes. By contrast, gender had no significant relationship with athletes' total mean SCA. The result of age is not surprising because experienced (older athletes) tends to perceive sport competition from a more positive perspective, as they are more exposed to several competitions and that positively reflects on self-effectiveness which, in turn, increases self-confidence which also favours the development of more effective coping strategies to deal with criticism from oneself and others. The finding is not consistent with Parnabas and Mahamood [10] and Rocha and Osorio [2], who found that the level of anxiety tends to be higher in groups of young athletes due to the fact that their young age is directly related to factors, such as: feeling of insecurity, emotional dependency and use of less elaborated strategy for coping with the physiological responses [35]. Age has been found to be an important factor in determining competition anxiety [13]. The result on the type of sport is not surprising because being part of a team alleviates some pressure experienced by those who compete alone. The result is consistent with other studies $[2,6$, 36,37 ] which found that athletes who practice individual sports are more anxious during competition because of the responsibility of achieving result which depends exclusively on one person only; whereas those practicing team sport would share this responsibility with other members of the team. Also, the finding on type of sport agrees with Khan [38] who found a significant difference in both individual (boxing, badminton) and team (volleyball) sport competition anxiety, but which differed where individual game players had a higher level of sport competition anxiety than team players. The result on gender is surprising and not expected because conventionally females are expected to have a higher anxiety level than males. Also, males tend to have natural competitiveness, the urge to perform better and are more ego-oriented than females. This result is consistent with Jones [30], who found that at the top sporting level, there is a very little difference in the participants' skill level. It is thus often the ability to handle arousal, anxiety and stress that differentiate the winner and the loser. The result is also consistent with Stegall [39], who found no significant difference between male and female levels of anxiety in a study conducted in the southern part of the United States of America, and with Hassan et al. [40], who in a similar study among netball players in India found no significant difference between male and female netball players' anxiety level. The result is not in line with Reigal et al. [41], who reported that gender was significantly associated with psychological profile, competitive anxiety, moods and self-efficacy in beach handball players. The result also conflicts with some other studies [2, 10,42] which found that the female athletes had a higher competitive state and trait anxiety level than their male counterparts. This fact was corroborated by a meta-analysis showing significant differences in all dimensions, mainly in the trait SCA [2]. The results have implications for school coaches and sport psychologists in designing expertise training programmes to address adequately effective coping strategies to deal with anxiety in sport. In competitive anxiety, males report using more approach coping than females [17]. In the neurological perspective of psychopathology, these findings are supported by the literature showing a higher prevalence of anxiety symptoms and disorders 
in females due to the fact that the oscillating levels of gonadal hormones occur more often clinically in women than in men, which increases the susceptibility of the former to stress and anxiety $[43,44]$.

Table 5 shows that gender had a significant relationship with total mean PCS score, as females had greater PCS than their male counterparts. Age had a significant relationship with total mean PCS score, as older athletes had greater PCS than younger athletes. The type of sport had a significant relationship with the total mean PCS score, as team sport athletes had greater PCS than individual sport athletes. The results are expected because when athletes at any level are under pressure from the demands of their sports and do not have an adequate coping mechanism in place to withstand it, it usually has a detrimental effect on performance. Therefore, there is a need to be focus on increasing the amount and diversity of athletes' coping skills since suppressing and ignoring stressor anxiety has a negative impact on an individual performance as well as his or her wellbeing. The findings agree with the report by Bamuhair et al. [15] that females seek social support more often while increasing their effort to manage goal frustration. In terms of the stress and anxiety level, females tend to report a higher level of stress compared to males. Females also typically report use of more negative coping styles, such as: avoidance, mental and physical withdrawal [16]. An initial study by Gross and Hen [45] found that female athletes feel more in control and selfsufficient when it comes to coping and as well report less avoidant coping style than male athletes. In contrast, Gnacinski et al. [46] found that females reported lower self-efficacy in terms of their ability to apply their established coping skills when faced with mentally stressful barriers or obstacles. Female athletes also use more emotion-focus coping than males, and females are more likely to use coping driven by emotion while males use problemoriented coping $[18,19]$. The result on gender is not consistent with Kruger and Pienaar [47], who found that male and female groups did not differ significantly or practically in any of the seven subscales of sport psychological coping skills. The result on age is surprising and not expected though different types of stress and anxiety level are encountered as individual aged, and these differences in stress and anxiety exert an impact on coping strategies and health outcomes. However, studies have found that older athletes exhibit better coping strategies and are more likely than their younger counterparts to perceive the cognitive type of anxiety as facilitating their performance [48, 49]. The finding conflicts with the report of Rocha and Osorio [2] that young age is directly related to factors such as feeling of insecurity, emotional dependency and use of less elaborated coping strategy for coping with physiological responses, stressing that older athletes tend to perceive the competition from a more positive perspective as they are more exposed to increased self-confidence during contests which favours the development of more strategies to deal with criticism from oneself and others. As one advances in age, their repertoire of coping increases [50]. Folkman and Lazarus' [51] transactional model of stress and coping maintained that coping strategies vary depending on different types of stressors and that age differences in coping strategies may be as a result of changes in what people must cope with as they age. By implication, school coaches and sport psychologists are to always provide teaching and training methods based on the athlete's characteristics and development, whereas a sport psychologist should provide individualized feedback mechanisms to improve coping strategies through pep talks and motivation. The result on type of sport is expected and not surprising because being part or member of a team alleviates some pressure experienced by those who compete alone because there is shared ideas, cooperation and collaborative effort fond in a team. The findings provide support from a dispositional context to suggest that sport type and the level of competitive experience influence interpretation of symptoms usually experienced in pressure situations. 


\section{STRENGTHS, LIMITATIONS AND FUTURE DIRECTIONS}

The strengths of this study include using both male and female athletes as participants. Our findings can be used to initiate an intervention programme for high risk athletes on high anxiety trait on sport competitions and consequently used for follow-up evaluations on the efficacy and effectiveness of the programme. However, there are some limitations in the study. First, the study was cross-sectional in nature, limiting our ability to infer causality (cause-effect relationships), meaning we reported only the information provided on significant associations between sport competition anxiety and psychological coping skills and their covariates, and it cannot be used to infer causality of these events, which would require clinical trials and longitudinal studies. Also, in this study, data were collected retrospectively, this might introduce recall bias. A participant's ability to recall about how they feel in a competitive situation, including the frequency and duration may also be questionable. Recall accuracy was improved by reducing the time frame between the discrete event and the length of the recall period. For instance, this study employed recall in the anxiety trait and psychological coping skills in the past 12 months. Second, the use of a questionnaire alone to collect data may lack precision to quantify high levels of anxiety or less strength on psychological coping skills, and are subject to recall and reporting bias, which may result in some degree of misclassification. Our study sample consisted of only the secondary school athletes, and does not include non-collegiate athletes who belong to other clubs, thus limiting the generalizability of the findings. Future studies should consider using a larger, randomized and more representative sample size, considering other associated factors of sport competition anxiety and athletes in general, and also including adoption of a qualitative research approach. Moreover, this study only employed a measure of trait anxiety. To provide a more comprehensive understanding of competitive anxiety, future research should incorporate state anxiety measures, but also individual or environmental variables that might predict anxiety symptoms, such as: a coach's interpersonal style and intrinsic and extrinsic motivation.

\section{CONCLUSIONS}

The findings have shown that secondary school athletes in Enugu State, South East Nigeria, had an average level of anxiety and greater strength on psychological coping skills while participating in sport competition. Athletes with higher COACH had greater Sport Competition Anxiety (SCA) than those with lower COACH. Athletes with lower GOAL had greater SCA than those with higher GOAL, and athletes with higher FREE had greater SCA than those with lower FREE. Male athletes more often had an average level of anxiety while participating in sport competition than the female athletes, though not significantly. Older athletes had greater SCA than younger athletes, while team sport athletes had greater SCA than individual sport athletes. In view of the obtained results, one can conclude that SCA is a phenomenon occurring in the sports context which deserves attention as it is closely related to the athlete's quality of life and performance, being more significantly associated with COACH, GOAL and FREE dimensions of athletic coping skills, and older and team sport athletes. Female athletes had greater strength on psychological coping skills (PCS) than male athletes. Older athletes had greater strength on PCS than younger athletes while team sport athletes had greater strength on PCS than individual sport athletes. The results indicate the importance of including the training of psychological skills in the training processes of school athletes. However, sports psychologists, Physical Education teachers and school coaches should use the findings to design appropriate training programmes to help secondary school athletes acquire suitable coping strategies so as to reduce their sport competition anxiety levels and enhance their performance. Sport psychologists, Physical Education teachers, games masters/mistresses and coaches in secondary schools need to acquire psychological skills through specialized seminar or expertise training so as to enable athletes to cope with sport anxiety. There is a need to identify situations that are likely to 
cause a high level of anxiety and lower psychological coping strength so that appropriate self-regulation and anxiety management techniques can be deployed considering factors such as age, gender and type of sport. Awareness campaign programmes should be increased by sport agencies in Nigeria through every available media on anxiety and the effect on school athletes' performance. Studies should consider exploring associations of Competition Anxiety level with psychological, physiological and relational variables.

\section{ACKNOWLEDGEMENTS}

We would like to express our sincere gratitude to the various schools, school Principals and sports personnel that permitted us to study their subjects. We sincerely appreciate all the male and female athletes involved in the study for their cooperation and provision of necessary information. We would also like to express our appreciation for the constructive review done by two anonymous reviewers that helped to improve the manuscript prior to submission.

\section{REFERENCES}

[1] Muhammad KK, Alamgir K, Sami UK. Effect of anxiety on athletic performance. Res Inves Sports Med. 2017;1(1): 19-23. https://doi.org/10.31031/RISM.2017.01.000508

[2] Rocha VVS, Osorio FL. Associations between competitive anxiety, athlete characteristics and sport context: Evidence from a systematic review and meta-analysis. Arch Clin Psychiatry. 2018;45(3):67-74. https://doi.org/10.1590/010160830000000160

[3] Malina RM, Cumming SP. Current status and issues in youth sports. In: Malina RM \& Clack MA, editors. Youth sports: Perspective for a new century. Montery, CA: Coaches Choice; 2003, 7-25.

[4] Lizuka P. Anxiety and performance in young table tennis players. Sport Sci Res. 2005;26(3):73-75.

[5] Weinberg RS, Gould D. Foundation of sport and exercise psychology (6th ed.) Champaign, Ill.: Human Kinetics Press; 2015.

[6] Moran A. Sports and exercise psychology. London: Routledge; 2004. https://doi.org/10.4324/9780203380246

[7] Reigal RE, Delgado-Giralt J, Lopez-Cazorla R, Hernandez-Mendo A. Sports psychological profile and competitive state anxiety in triaathletes. Rev Psicol Deporte. 2018;27:125-132.

[8] Verner-Filion J, Vallerand RJ, Donahue EG, et al. Passion, coping, and anxiety in sport: The interplay between key motivational and self-regulatory processes. Int J Sport Psychol. 2014;45:516-537.

[9] Zamani AR, Moradi A. Comparison of trait anxiety, state anxiety and self-confidence between individual and group sports of male athletes in the country. Knowledge Res Q Appl Psychol. 2011;5(40):81-98.

[10] Parnabas VA, Mahamood Y. Competitive anxiety level before and during competition among Malaysian athletes. Pertanika J Soc Sci Hum. 2010;18(2):399-406.

[11] Asha SR. State and trait anxiety: A comparison of the on and off field anxiety levels of athletes and non-athletes [University Honors Program Theses]. Georgia Southern University; 2016.

[12] Bazancir Z, Beydagi MG. Effect of different Pre-competition anxiety and self-confidence on the performance in bouldering climbers. Gaziantep Universitesi Spor Bilimleri Dergisi. 2018;3(1):1-9.

[13] Bozkus TM, Kul M. The effect of age, sports experience and physical self-perception on competition anxiety level of female football players. Int J Acad Res. 2013; 5(4):509-513. https://doi.org/10.7813/2075-4124.2013/5-4/B.72

[14] Mesagno CA. Comparison of different pre-performance routines as possible choking interventions. J Appl Sport Psychol. 2010;22:343-360. https://doi.org/10.1080/10413200.2010.491780

[15] Bamuhair SS, Al Farhan AI, Althubatiti A, Agha S, Rahman S, Ibrahim NO. Sources of stress and coping strategies among undergraduate medical students enrolled in problem-based learning curriculum. J Biomed Educ. 2015;1-8. https://doi.org/10.1155/2015/575139

[16] Hoar SD, Evans MB, Link CA. How do master athletes cope with pre-competition stress at a senior games. J Behav. 2012;35(2):181-203.

[17] Anshel MH, Kang M, Miesner M. The approach-avoidance framework for identifying athletes' coping style as a function of gender and race. Personal Soc Sci. 2010; 51:341-349. https://doi.org/10.1111/j.1467-9450.2009.00796.x

[18] Hammermister J, Burton D. Gender differences in coping with endurance sport stress: are men from Mars and women from Venus. J Sport Behav. 2004;27:148-164.

[19] Nicholls AR, Polman RJ, Ley VR, Taylor J, Cobley S. Stressors, coping and coping effectiveness: Gender, type of sport and skill differences. J Sport Sci. 2007; 25(13): 1523-1530. https://doi.org/10.1080/02640410701230479

[20] Enugu State Sport Office of the Post Primary School Management Board. Statistics of Secondary School Students. $\square$ Statistics of students. 2019.

[21] Charan J, Biswas T. How to calculate sample size for different study designs in medical research. Ind J Psychol Med. 2013;35:121-6. https://doi.org/10.4103/0253-7176.116232

[22] Martens R. Sport Competition Anxiety Test; Human Kinetics: Champaign, IL, USA; 1977. https://doi.org/10.1037/t27556-000

[23] Martens R, Burton D, Vealey RS, Bump LA, Smith DE. Development and validation of the Competitive State Anxiety Inventory-2. In Competitive Anxiety in Sport; Martens, R., Vealey RS, Burton D. Eds. Human Kinetics: Champaign, IL, USA; 1990, 127-140. 
[24] Smith RE, Shutz RW, Smoll FL, Ptacek JT. Development and validation of a multidimensional measure of sportspecific psychological skills: the athletic coping skills inventory-28. J Sport Exerc Psychol. 1995;17:399-415. https:// doi.org/10.1123/jsep.17.4.399

[25] American Psychological Association (APA). Ethical principles of psychologists and code of conduct. 2010 December [Available at http://www.apa.org/ethics/code/principles.pdf] [Accessed on 4th January, 2020]

[26] Bryne B. Structural equation modeling with AMOS. In Basic Concepts, Applications, and Programming. New York, NY, USA: Taylor \& Francis Group LLC; 2010.

[27] Hanton S, Thoman O, Maynard I. Investigating the competitive anxiety responses in the week leading up to competition: The role of intensity, direction and frequency dimensions. Psychol Sport Exerc. 2002;5:169-181. https:// doi.org/10.1016/S1469-0292(02)00042-0

[28] Males JR, Kerr JH. Stress, emotion and performance in Elite Slalom Canoeist. Sport Psychol. 1996;10:17-36. https:// doi.org/10.1123/tsp.10.1.17

[29] Cunniffe B, Morgan KA, Baker JS, Cardinale M, Davies B. Home versus away competition: Effect on psychophysiological variables in Elite Rugby Union. Int J Sports Physiol Perform. 2015:10(6):687-94. https://doi.org/10.1123/ijspp.2014-0370

[30] Jones G. Recent developments and current issues in competitive state anxiety research. Psychol. 1991;7:152-155.

[31] Andrade E, Spain S, Rodriguez D. Precompetitive mood factors in collective sports adolescents and satisfaction: With performance. J Sport Psychol. 2016;25:229-236.

[32] Crocker PRE, Tamminen KA, Gaudreau P. Coping in sport. In: Hantn S., Mellalieu S., Eds. Contemporary advances in sport psychology: A review. New York: Routledge; 2015,28-67.

[33] Flores-Moreno PJ, Perez-Ruvalcaba SL, Salazar C, et al. Sources, symptoms and strategies for coping with stresscompetitive swimmers. Rev Psicol Deporte. 2017;26:199-208.

[34] Nicholls AR, Hoh NL, Polman RJ, Bloomfield J. Stressors, coping and coping effectiveness among professional rugby union players. Sport Psychologist. 2006;20(3):314-329. https://doi.org/10.1123/tsp.20.3.314

[35] Modrono C, Gullen F. Anxiety characteristics of competitive windsurfers: Relationships with age, gender, and performance outcomes. J Sport Behav. 2011:34(3):281-94.

[36] Kirby RJ, Liu J. Precompetition anxiety in Chinese athletes. Percept Motor Skill. 1999;88:297-303. https://doi. org/10.2466/pms.1999.88.1.297

[37] Ramis Y, Torregrosa M, Cruz J. Martins revisited: Competitive anxiety in youth sports. Rev Psicolog Deporte. $2013 ; 22: 77-83$

[38] Khan SMO. Comparative study of sports competition anxiety among the different male athletes in Medhay Predesh India: DAVV; 2017

[39] Stegall ASR. State and trait anxiety: A comparison of the on and off-field anxiety levels of athletes and non-athletes 2016. University Honors Program Theses. 224. https://digitalcommons.georgiasouthern.edu/honors-theses/224

[40] Hassan A, AhmadBlat J, Shelvam PV. Sport competition anxiety among netball players. The International Journal of Indian Psychology. 2016; 4. https://doi.org/10.25215/0401.017

[41] Reigal RE, Vazquez JA, Morillo-Baro JP, Hermandez-Mendo A, Morales-Sanchez V. Psychological profile, competitive anxiety, mood and self-efficacy in Beach Handball players. Int J Environ Res Public Health. 2020;17:241. https:// doi.org/10.3390/ijerph17010241

[42] Bebetsos A, Antonio P. Competitive state anxiety and gender differences among Greek Badminton players. J Phys Educ Sport. 2012;1.

[43] Maeng LY, Milad MR. Sex differences in anxiety disorders: interactions between fear, stress, and gonadal hormones Horm Behav. 2015:76:106-17. https://doi.org/10.1016/j.yhbeh.2015.04.002

[44] Marques AA, Bevilaqua MCN, Fonseca AMP, Nardi AE, Thuret S, Dias GP. Gender differences in the neurobiology of anxiety: Focus on hippocampal neurogenesis. Neural Plast. 2016:2016:1-14. https://doi.org/10.1155/2016/5026713

[45] Gross C, Hen R. The developmental origins of anxiety. Nat Rev Neurosci. 2004;5(7):545-52. https://doi.org/10.1038/ nrn1429

[46] Gnacinski SL, Massey WV, Hess CW, Nai MM, Arvinen-Barrow M, Meyer BB. Examining stages of change differences in NCAA student-athletes readiness for psychological skills training. Sport Psychologist. 2017;31(4):356-368. https:// doi.org/10.1123/tsp.2016-0139

[47] Kruger A, Pienaar AE. Gender differences in the sport psychological skills profile of adolescent sport participants Int Sport Med J. 2014;15(4):474-482.

[48] Craft LL, Maygar TM, Becker BJ, Feltz DL. The relationship between the competitive state anxiety inventory-2 and sport performance: A meta-analysis. J Sport Exerc Psychol. 25:44-65. 2003. https://doi.org/10.1123/jsep.25.1.44

[49] Cruz JF, Dias C, Fonseca AM. Coping strategies, multidimensional competitive anxiety and cognitive threat appraisal: Differences across sex, age and type of sport. Serb J Sport Sci. 2010;1:4-9.

[50] Holt NL, Mandigo JL. Coping with performance, worries among young male cricket players. J Sport Behav. 2004;27(1):39-57.

[51] Folkman S, Lazarus RS. Stress process and depressive symptomology. J Abnorm Psychol. 1986; 95:107-113. https:// doi.org/10.1037/0021-843X.95.2.107

Cite this article as:

Iwuagwu TE, Umeifekwem JE, Igwe SN, Oforka OK, Udeh OP.

Profile of sport competition anxiety trait and psychological coping skills among secondary school athletes in Enugu State, South East Nigeria

Balt J Health Phys Act. 2021;Suppl(2):75-87

doi: 10.29359/BJHPA.2021.Suppl.2.08 